\title{
SISTEM INFORMASI PEMBELIAN DAN PENJUALAN PAKAIAN PADA GALOENK DISTRO PEMATANGSIANTAR
}

\author{
Victor Marudut Mulia Siregar \\ Politeknik Bisnis Indonesia; Pematangsiantar - Sumut \\ victor.siregar2@gmail.com
}

\begin{abstract}
ABSTRAK - Galoenk Distro merupakan sebuah toko yang bergerak dalam bidang penjualan pakaian di kota Pematangsiantar. Pengolahan data penjualan barang pada Galoenk Distro masih dilakukan dengan mencatat transaksi secara manual pada faktur penjualan dan buku kas, sehingga pengontrolan stok pakaian maupun proses pembuatan laporan kurang efisien. Perancangan sistem informasi pembelian dan penjualan pakaian ini dilakukan untuk mengatasi kurang efisiennya pengolahan data pembelian dan penjualan pada toko tersebut. Sistem informasi ini memberikan kemudahaan dalam pengolahan data transaksi penjualan dan pembelian serta meminimalisir kesalahan yang terjadi dalam pencatatan data pembelian dan penjualan per periode, sehingga menghasilkan laporan penjualan dan pembelian yang lebih tepat dan akurat.
\end{abstract}

Kata Kunci : Sistem Informasi, Penjualan, Pembelian, Efisien, Akurat, Distro

ABSTRACT - Galoenk Distro is a shop that specializes in clothing sales in the city of Pematangsiantar. The data processing of goods sales at Galoenk Distro is still done by recording transactions manually on sales invoices and cash books, so controlling the stock of clothing as well as the process of making reports is less efficient. The design of clothing purchase and sales information systems is carried out to overcome the inefficient processing of purchasing and selling data at the store. This information system provides convenience in processing sales and purchase transaction data and minimizes errors that occur in recording data on purchases and sales per period, so as to produce sales reports and purchases that are more precise and accurate.

Keywords: Information Systems, Sales, Purchasing, Efficient, Accurate, Distro

I. PENDAHULUAN

Saat ini perkembangan teknologi informasi semakin pesat. Pemanfaatan teknologi informasi dapat memberi kemudahan dalam pengolahan informasi serta dapat mengurangi terjadinya kesalahan dalam proses pengarsipan data. Penggunaan teknologi informasi yang optimal dalam sebuah perusahaan akan menunjang efesiensi dan efektifitas kerja dalam mengolah data untuk mendapatkan informasi yang dibutuhkan.

Galoenk Distro Pematangsiantar merupakan sebuah toko yang bergerak dalam bidang penjualan pakaian seperti baju, celana, topi, tas dan sepatu. Dalam melakukan transaksi, distro ini masih melakukan pencatatan transaksi dengan cara manual dan laporannya masih dilakukan secara manual yaitu dengan mencatat transaksi pada faktur penjualan dan buku kas, sehingga pengontrolan stok pakaian maupun proses pembuatan laporan kurang efisien.

Agar pendataan proses transaksi pembelian dan penjualan lebih efisien, dibutuhkan pembangunan sebuah sistem informasi yang dapat membantu memperlancar pencatatan transaksi.

Pembangunan sistem informasi sudah banyak dilakukan untuk memecahkan masalah, antara lain : perancangan sistem informasi akademik 
yang berbasis web untuk membantu pihak sekolah dalam mengelola administrasi data sekolah di SMP Negeri 2 Kecamatan Gaung [1], perancangan sistem informasi pendataan penduduk untuk membantu proses pembuatan surat-surat kependudukan pada Kecamatan Gadingrejo [2], membangun sebuah Sistem Informasi Penjualan dan Pemesanan Layanan Berbasis Web dan SMS Gateway di Petshop PetZone [3], dan lain-lain.

Dari contoh-contoh tersebut, dapat dilihat bahwa penerapan Sistem informasi sangat membantu efisiensi kerja sebuah perusahaan/instansi.

Oleh karena itu, untuk mengatasi masalah kurang efisiennya pengolahan data transaksi penjualan maupun pembelian pada perusahaan Galoenk Distro Pematangsiantar, maka dirancang suatu Sistem Informasi Pembelian dan Penjualan. Sistem Informasi ini diharapkan dapat meningkatkan kinerja Galoenk Distro dalam proses pencatatan transaksi pembelian dan penjualan, serta pembuatan laporan pembelian dan penjualan pakaian.

\section{TINJAUAN PUSTAKA}

\section{A. Sistem Informasi}

Sistem adalah kumpulan dari rangkaian komponen-komponen yang saling berhubungan dan saling bekerja sama sebagai satu kesatuan organik untuk mencapai suatu tujuan yang sama serta dapat mempengaruhi sebagian yang akan mempengaruhi keseluruhan [4].

Informasi adalah data yang telah diolah sedemikian rupa ke dalam suatu bentuk yang lebih berarti bagi penerimanya yang menggambarkan suatu kejadian-kejadian yang nyata, sehingga bermanfaat dan dapat digunakan dalam proses pengambilan keputusan saat ini dan saat mendatang [5].

"Sistem informasi adalah suatu alat untuk menyajikan informasi sedemikian rupa sehingga bermanfaat bagi penerimanya." [2].

\section{B. Konsep Penjualan}

Penjualan adalah persetujuan kedua belah pihak antara penjual dan pembeli, dimana penjual menawarkan suatu produk dengan harapan pembeli dapat menyerahkan sejumlah uang sebagai alat ukur produk tersebut sebesar harga jual yang telah disepakati [6].

Penjualan bila diidentifikasikan berdasarkan perusahaannya maka dapat dikategorikan menjadi beberapa jenis, yaitu : 1. Penjualan langsung dimana penjualan ini adalah dengan cara mengambil barang dari supplier kemudian secara langsung dikirim ke customer 2. Penjualan stok gudang dimana penjualan ini adalah dengan cara menjual barang dari stok yang ada di gudang. 3. Penjualan kombinasi adalah penjualan dimana dengan mengambil sebagian barang dari supplier serta sebagian dari stok yang ada di gudang [7].

\section{Data Flow Diagram (DFD)}

Data Flow Diagram (DFD) adalah model logika data atau proses yang dibuat untuk menggambarkan dari mana asal data dan kemana tujuan data yang keluar dari sistem, dimana data disimpan, proses apa yang dihasilkan data tersebut dan interaksi antara data yang tersimpan dan proses yang akan dikenakan pada data tersebut [8]. 


\section{Bahasa Pemrograman}

Bahasa pemrograman, atau sering diistilahkan dengan bahasa komputer, merupakan teknik komando atau instruksi standar untuk memerintah komputer. Bahasa pemrograman dapat dimanfaatkan untuk membagun sebuah sistem aplikasi sesuai dengan kebutuhan yang dapat dimanfaatkan dalam berbagai bidang baik dalam bidang pendidikan, ekonomi, bisnis bahkan dalam bidang sosial budaya [6].

Perangkat lunak yang digunakan untuk membangun sistem informasi ini adalah Microsoft Visual Studio 2012 yang merupakan sebuah perangkat lunak yang dapat digunakan untuk melakukan pembangunan aplikasi, baik itu aplikasi bisnis atau aplikasi personal dalam bentuk aplikasi console, aplikasi Windows ataupun aplikasi web.

\section{METODE PENELITIAN}

\section{A. Analisis Sistem yang Sedang Berjalan}

Galoenk Distro merupakan sebuah toko yang berkembang dan bergerak dalam bidang pembelian dan penjualan pakaian. Berdasarkan pengamatan, transaksi pembelian dan penjualan pada Galoenk Distro dilakukan dengan cara mencatat transaksi secara manual pada faktur penjualan dan buku kas. Penjualan dilakukan secara tunai dengan model kombinasi yakni dengan mengambil sebagian barang dari supplier serta sebagian dari stok yang ada.

\section{PERANCANGAN SISTEM}

\section{A. Diagram Konteks}

Diagram

konteks menggambarkan hubungan antara entitas-entitas yang terdapat diluar sistem dan masukan serta keluaran pada sistem informasi Pembelian dan Penjualan Pada Galoenk Distro.

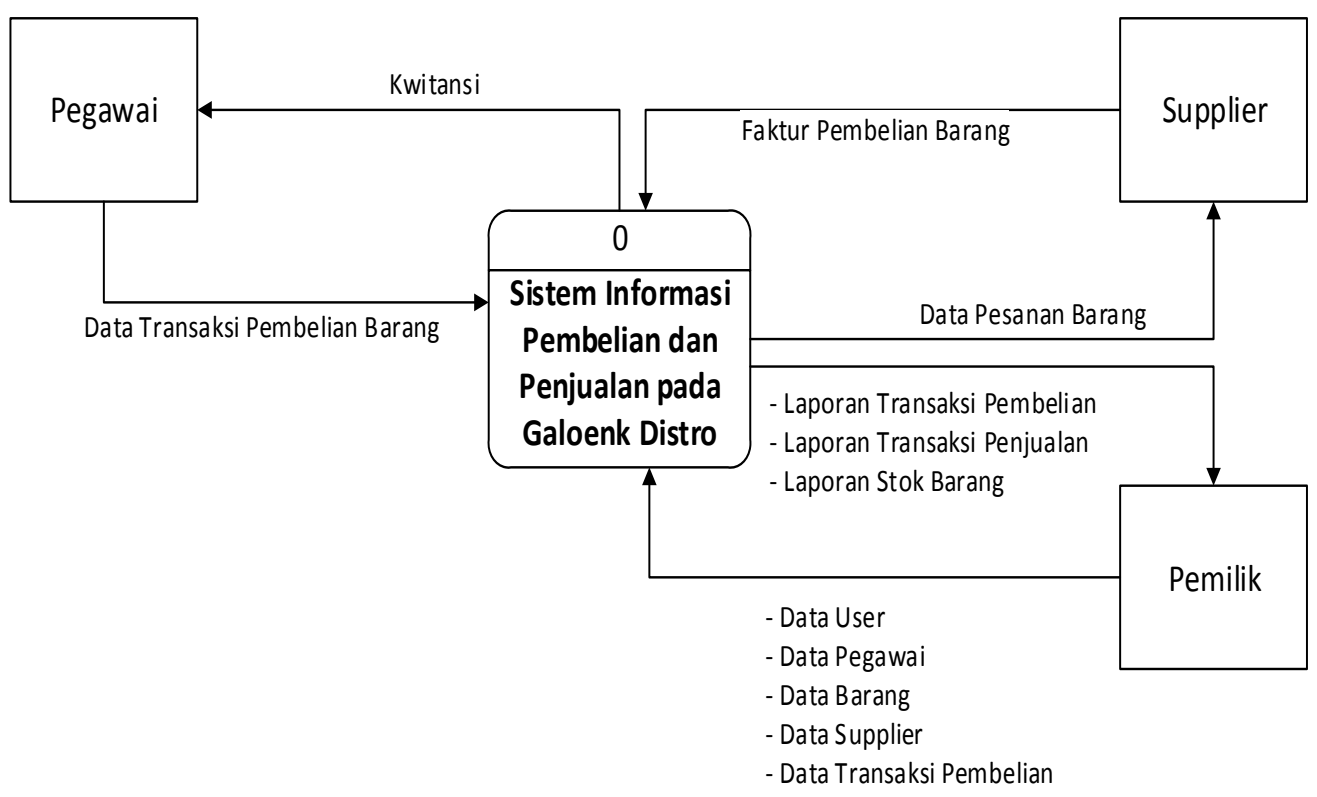

Gambar 1. Diagram Konteks 


\section{B. DFD Level 0}

Pada DFD Level 0 merupakan diagram yang digunakan untuk menggambarkan arus data secara detail pada sistem informasi pembelian dan penjualan pakaian pada Galoenk Distro. DFD Level 0 pada sistem informasi ini dapat dilihat pada gambar 2.

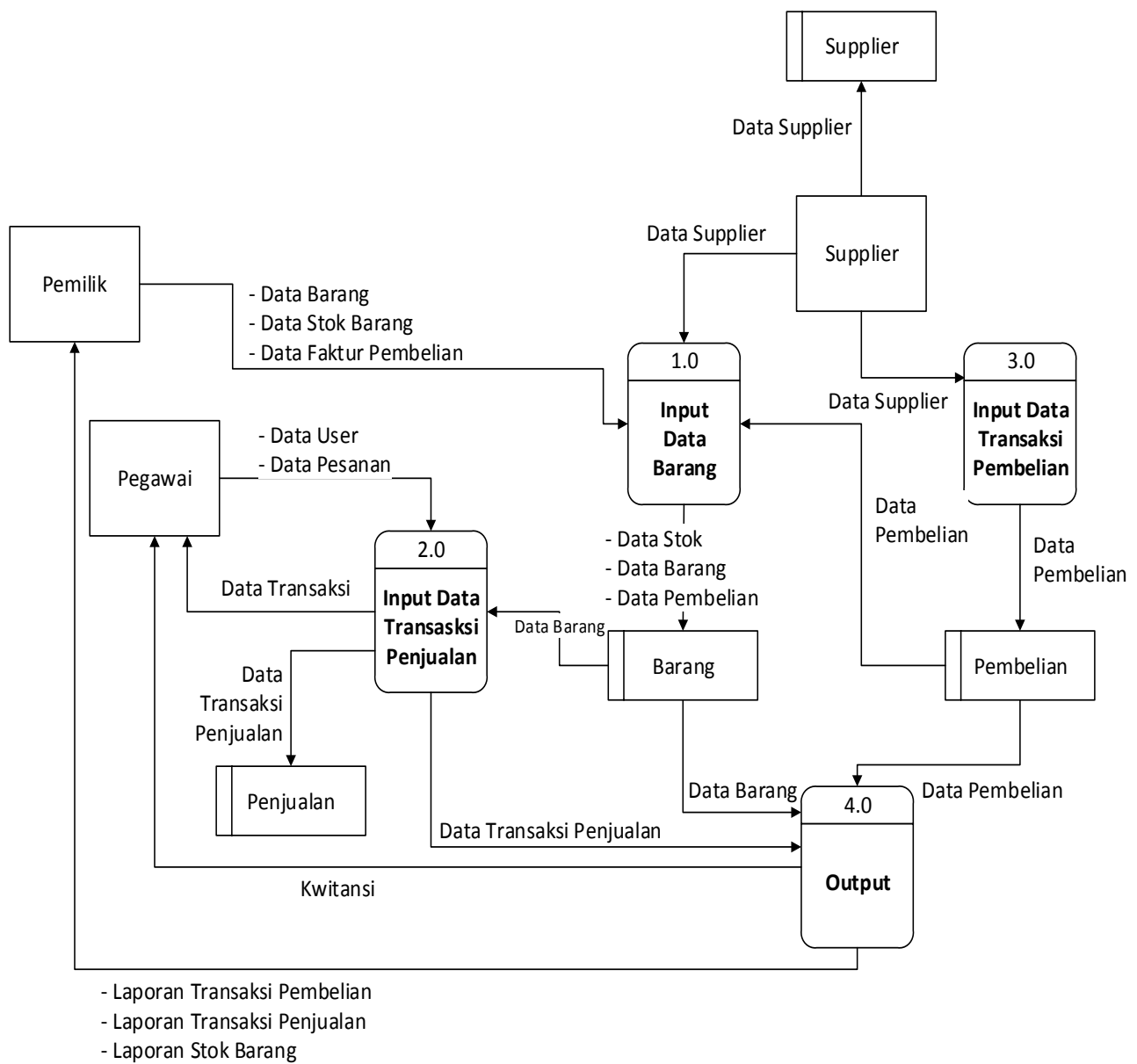

Gambar 2. DFD Level 0

\section{HASIL DAN PEMBAHASAN}

Adapun hasil dari implementasi sistem informasi pembelian dan penjualan pakaian pada Galoenk Distro Pematangsiantar ini antara lain :

\section{A. Halaman Login}

Sebelum masuk ke menu-menu dalam sistem, user pertama kali akan dihadapkan dengan halaman login. Pada halaman login, user harus menginputkan username dan password. Sistem akan memvalidasi apakah user memiliki otoritas untuk menggunakan sistem ini. 


\section{B. Menu Utama}

Setelah proses validasi selesai berikutnya user akan memasuki halaman menu utama yang merupakan halaman yang digunakan sebagai jembatan atau penghubung antar semua halaman yang digunakan pada program ini. Pada halaman menu utama ini terdapat beberapa menu seperti master data, transaksi, penyesuaian, laporan dan logout.

\section{Halaman Transaksi Pembelian}

Halaman transaksi pembelian ini digunakan untuk menyimpan, mengedit dan menghapus data transaksi pembelian barang. Pada halaman ini user juga dapat mencetak faktur pembelian dengan mengklik tombol cetak

Tampilan dari halaman transaksi pembelian dapat dilihat pada gambar 3.

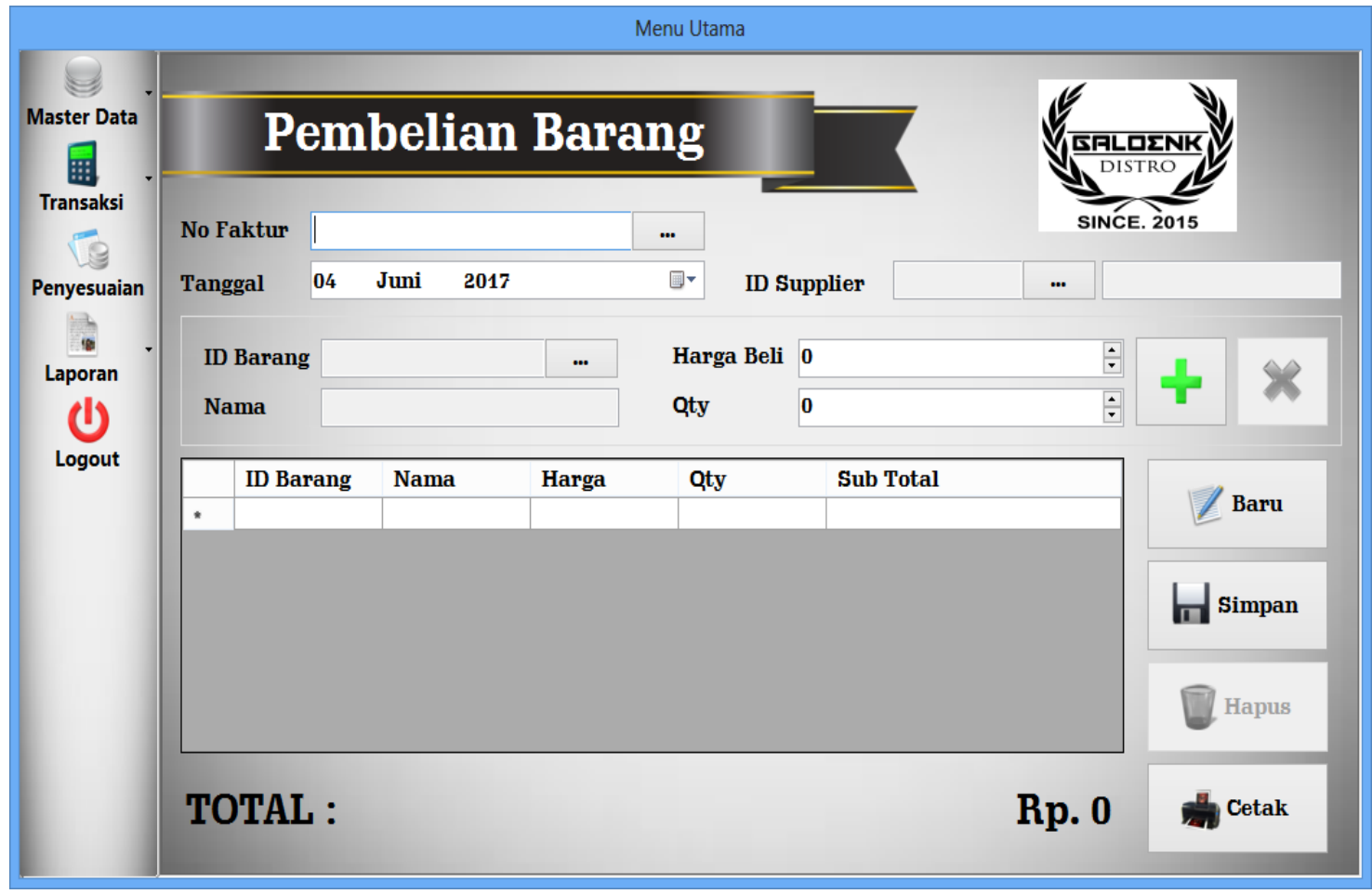

Gambar 3. Transaksi Pembelian

D. Transaksi Penjualan

Halaman transaksi penjualan ini digunakan untuk menyimpan dan mengedit data transaksi penjualan barang. Pada halaman ini user juga dapat mencetak nota penjualan dengan mengklik tombol cetak. Tampilan dari halaman transaksi penjualan barang dapat dilihat pada gambar 4. 


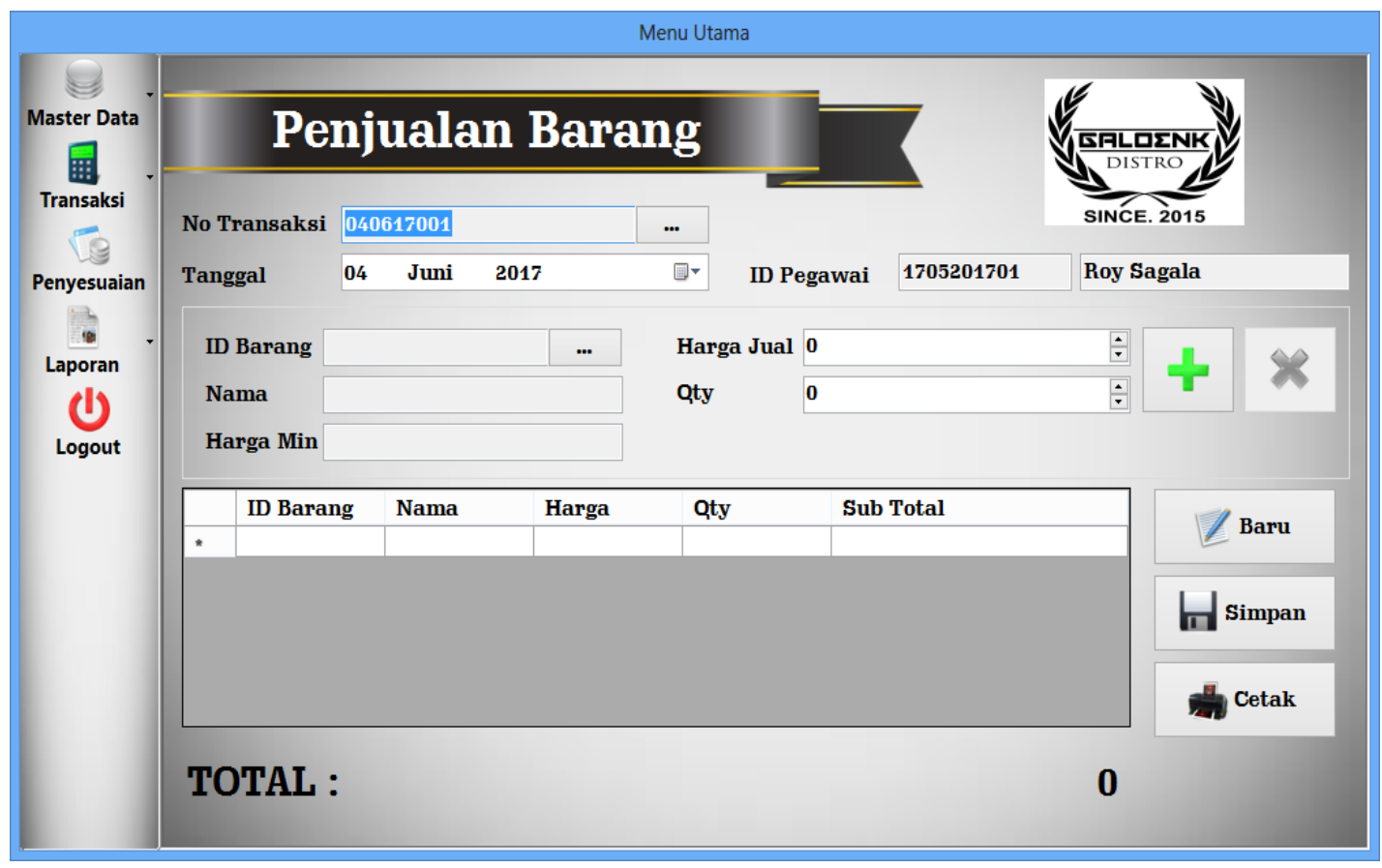

Gambar 4. Transaksi Penjualan

E. Form Penyesuaian Stok

Tampilan dari form penyesuaian stok dapat dilihat pada gambar 5 .

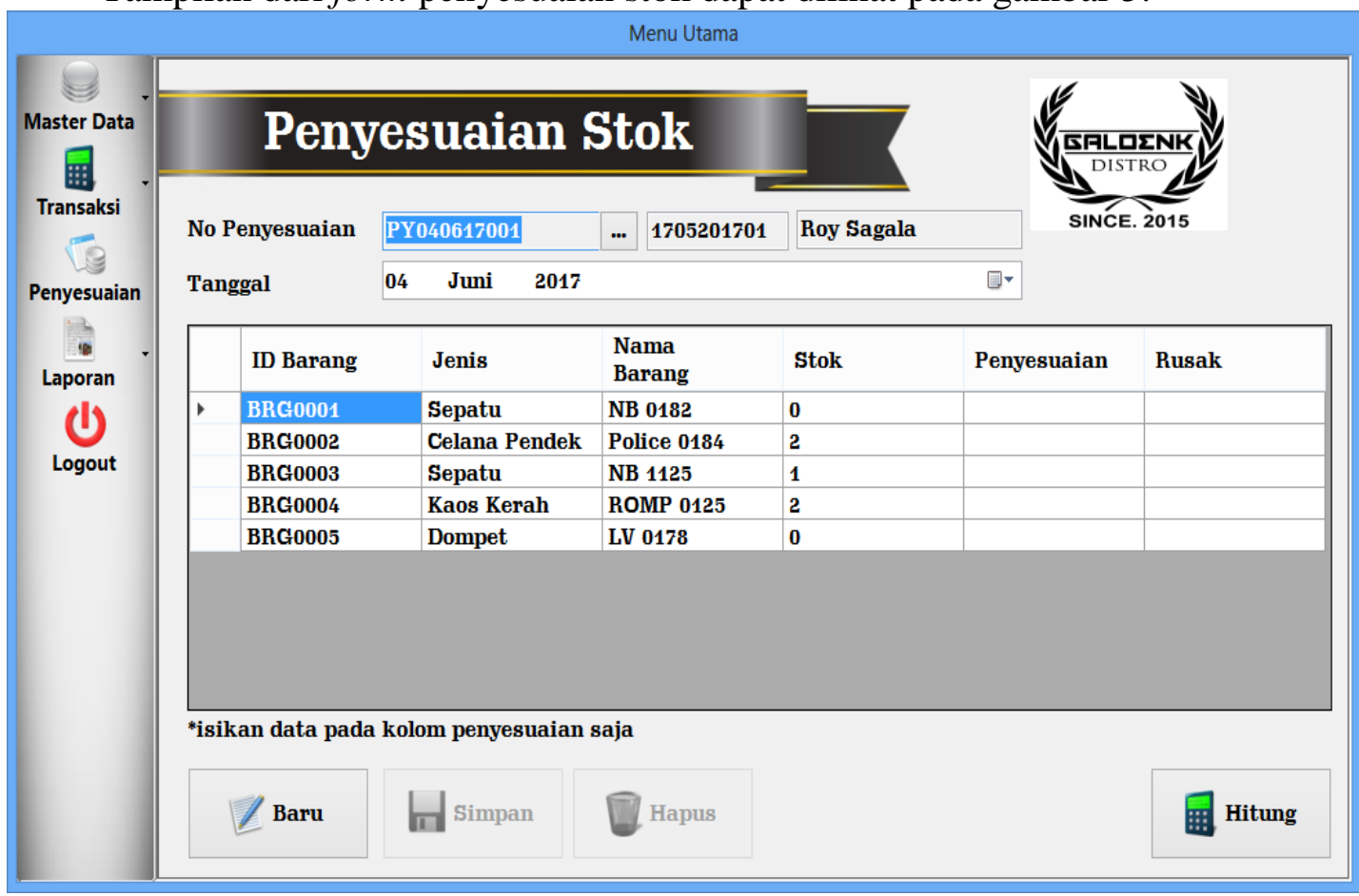

Gambar 5. Form Penyesuaian Stok 
F. Laporan Data Barang

Halaman laporan data barang dapat dijalankan dengan memilih menu master data, klik pada sub menu barang dan klik tombol cetak. Tampilan laporan data barang dapat dilihat pada gambar 6.

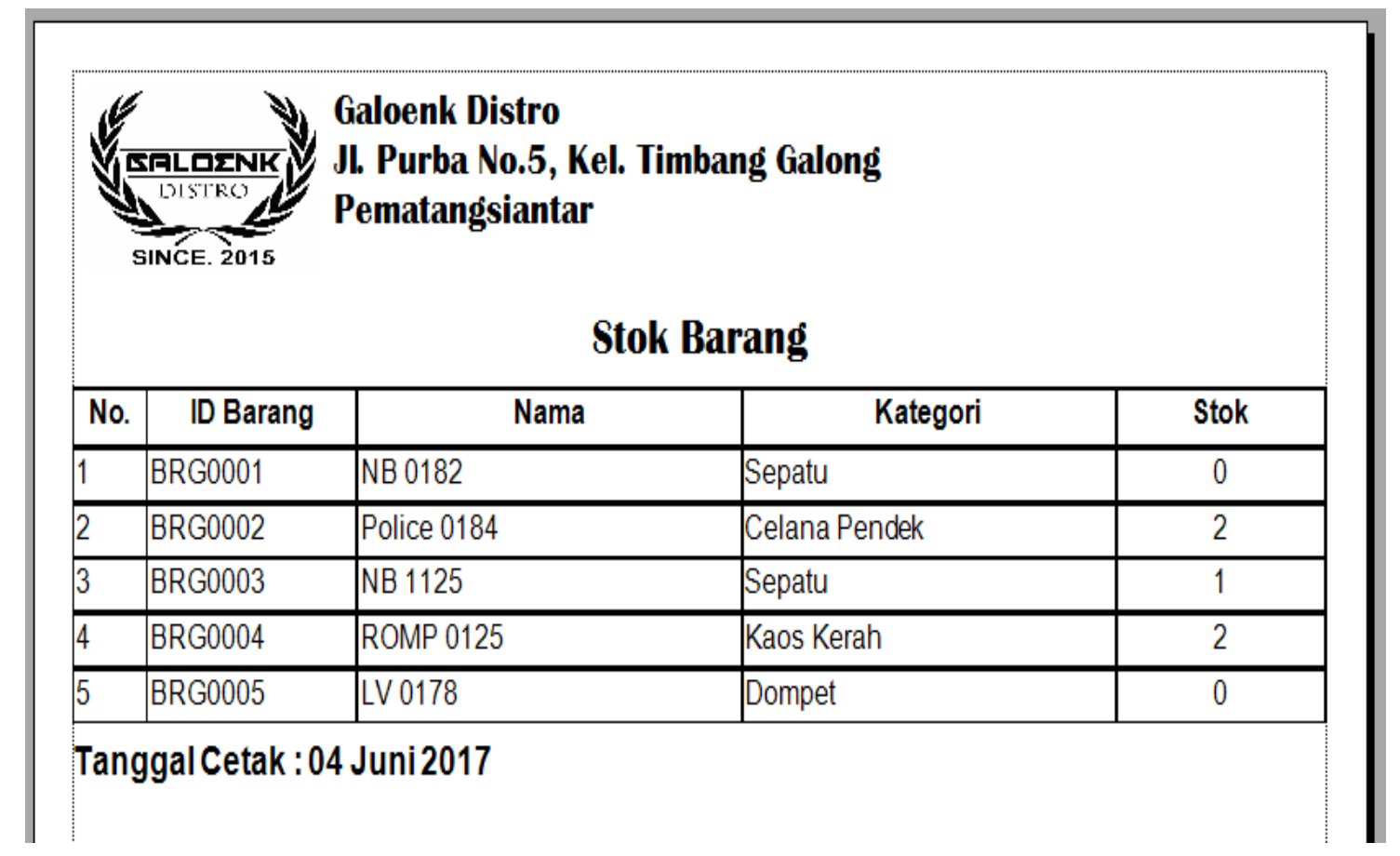

Gambar 6. Laporan Data Barang

\section{G. Nota Penjualan}

Halaman nota penjualan dapat dijalankan dengan memilih menu transaksi, klik pada sub menu penjualan dan klik tombol cetak. Tampilan nota penjualan dapat dilihat pada gambar 7 .

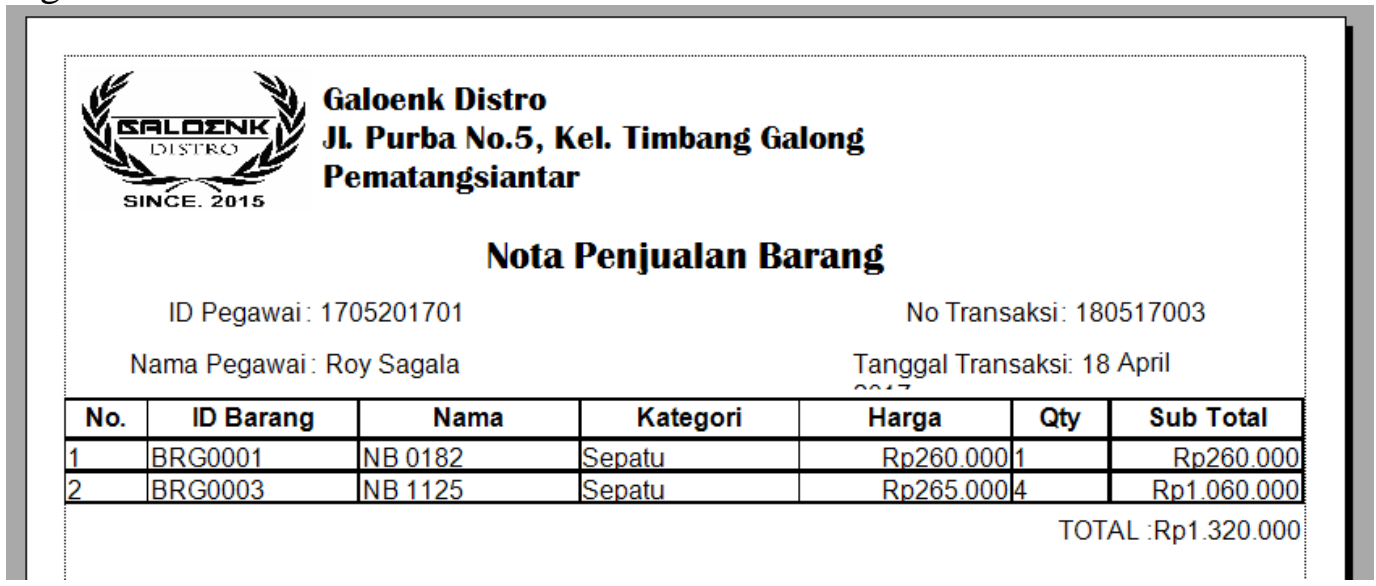

Gambar 7. Nota Penjualan 


\section{H. Laporan Penjualan Per Periode}

Halaman laporan penjualan per periode dapat dijalankan dengan memilih menu laporan dan klik pada sub menu penjualan per periode. Tampilan dari laporan penjualan per periode dapat dilihat pada gambar 8 .

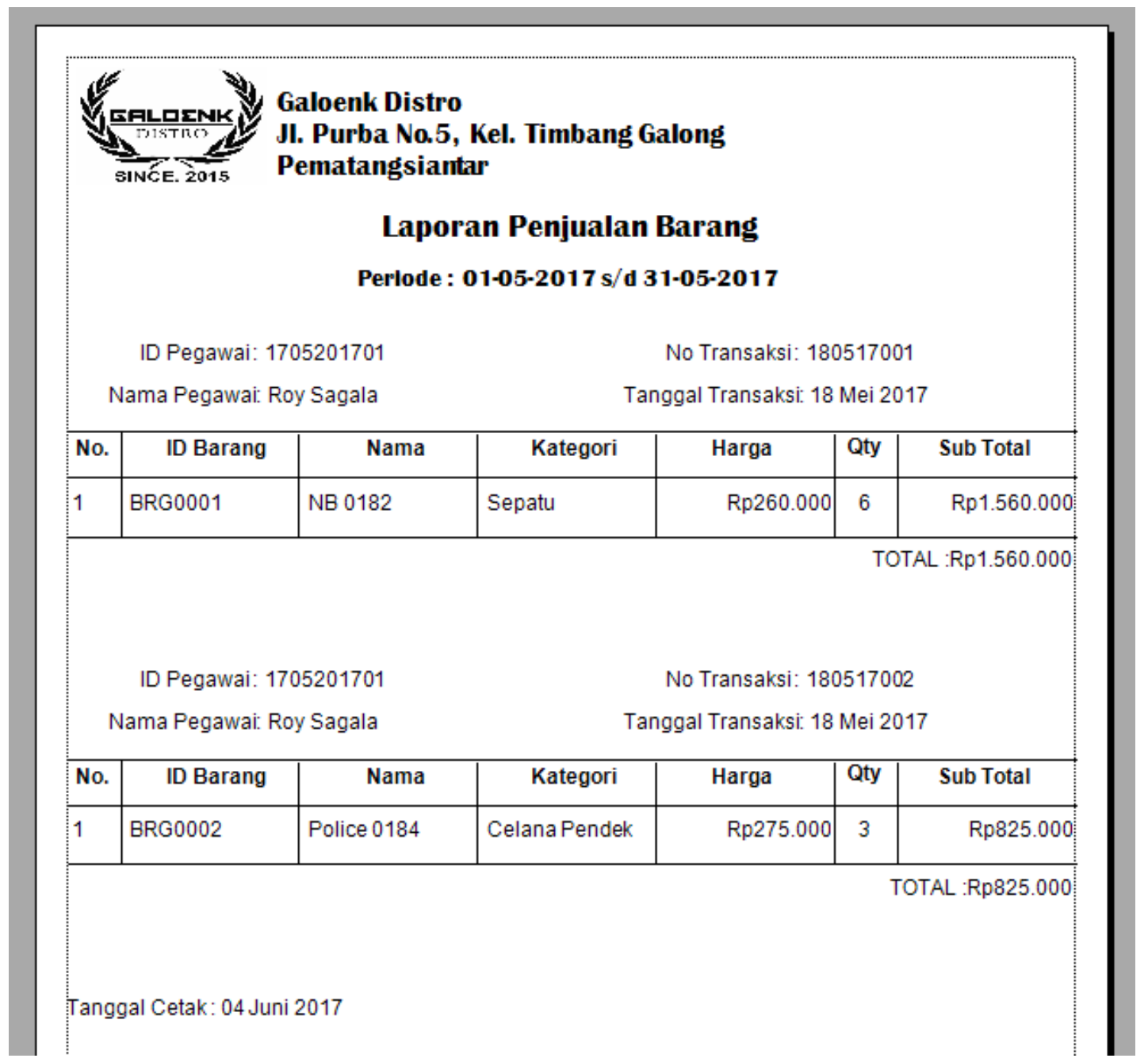

Gambar 8. Laporan Penjualan Per Periode

\section{KESIMPULAN}

Berdasarkan hasil implementasi Sistem informasi Pembelian dan Penjualan Pakaian pada Galoenk Distro Pematangsiantar dapat diambil kesimpulan, bahwa : a. Sistem Informasi Pembelian dan Penjualan Pakaian pada Galoenk Distro Pematangsiantar sangat membantu pihak toko khususnya dalam proses penyimpanan data transasksi pembelian dan penjualan pakaian. 
b. Sistem Informasi Pembelian dan Penjualan Pakaian pada Galoenk Distro Pematangsiantar telah meningkatkan kinerja toko dalam membuat laporan pembelian dan penjualan pakaian.

\section{SARAN}

Sistem Informasi Pembelian dan Penjualan Pakaian pada Galoenk Distro masih membutuhkan beberapa pengembangan, diantaranya sebagai berikut :

a. Pengembangan yang lebih spesifik seperti, keamanan sistem. Keamanan sistem yang dimaksud adalah dari segi penggunaan dan segi pengolahan data pada sistem yang dibuat sebaiknya ditingkatkan lagi agar lebih terjaga keamanan datanya.

b. Sistem informasi ini masih belum berbasis client server, diharapkan kepada pihak distro agar dapat mengembangkannya lebih baik lagi.

\section{DAFTAR PUSTAKA}

[1] M. R. Alpiandi, "Sistem Informasi Akademik berbasis web di SMP Negeri 2 Kecamatan Gaung," J. Sist. Inf. Akad., vol. Vol 5, no. 3, pp. 813, 2016.

[2] Ponidi and S. Fitrajaya, "Perancangan Sistem Informasi Pendataan Penduduk Berbasis Web Menggunakan Metode Waterfall Pada Kecamatan Gadingrejo," J. TAM (Technology Accept. Model., vol. 4, pp. 68-74, 2015.

[3] S. Fadhilah, A. F. Rochim, and R. Kridalukmana, "Sistem Informasi Penjualan dan Pemesanan Layanan Berbasis
Web dan SMS Gateway di Petshop PetZone," J. Teknol. dan Sist. Komput., vol. 1, no. 4, pp. 113-121, 2013.

[4] D. Irawan and S. Novita, "Sistem Informasi Manajemen Rumah Sakit Harapan Bunda Pringsewu Lampung," J. TAM (Technology Accept. Model., vol. 2, p. 48, 2014.

[5] A. Andoyo and R. Rianto, "Program Aplikasi Nilai Siswa Pada SMK Muhammadiyah Pringsewu Sebagai Penunjang Pengambilan Keputusan Siswa Berprestasi Menggunakan Visual Basic 6.0," J. TAM (Technology Accept. Model ), vol. 5, no. 2, pp. 58-65, 2015.

[6] E. Yulianto and T. Wijanarko, "Sistem Informasi Penjualan Secara Tunai Berbasis Web (Studi Kasus: Butik Belleza)," J. Teknol. Inf. dan Komun., vol. 6, no. 2, pp. 27-32, 2015.

[7] Anthony, A. R. Tanaamah, and A. F. Wijaya, "Analisis dan Perancangan Sistem Informasi Penjualan Berdasarkan Stok Gudang Berbasis Client Server (Studi Kasus Toko Grosir 'Restu Anda')," J. Teknol. Inf. dan Ilmu Komput., vol. 4, no. 2, pp. 136147, 2017.

[8] H. Asnal, "Sistem Penunjang Keputusan Untuk Menetapkan Kriteria Kelayakan Pengurus Badan Eksekutif Mahasiswa (BEM) Dengan Menggunakan Metode Analitycal Hierarchy Process (AHP), Study Kasus Pada STMIK-AMIK Riau," $J$. Teknol. dan Sist. Inf. UNIVRAB, vol. 2, no. 1, pp. 129-139, 2017. 